\title{
Evaluating the behaviour of curcumin nanoemulsions and multilayer nanoemulsions during dynamic in vitro digestion
}

\author{
Hélder D. Silva ${ }^{\mathrm{a}}$, Joana Poejo ${ }^{\mathrm{b}}$, Ana C. Pinheiro ${ }^{\mathrm{a}, \mathrm{c}, *}$, Francesco Donsì $^{\mathrm{d}}$, Ana Teresa Serra ${ }^{\mathrm{c}, \mathrm{e}}$, \\ Catarina M.M. Duarte ${ }^{\mathrm{c}, \mathrm{e}}$, Giovanna Ferrari ${ }^{\mathrm{d}, \mathrm{f}}$, Miguel A. Cerqueira ${ }^{g}$, António A. Vicente ${ }^{\mathrm{a}}$ \\ ${ }^{\text {a }}$ Centre of Biological Engineering, University of Minho, 4710-057 Braga, Portugal \\ ${ }^{\mathrm{b}}$ Department of Biochemistry and Molecular Biology, Faculty of Sciences, and Institute of Molecular Pathology Biomarkers, University of Extremadura, Badajoz, Spain \\ ' IBET, Instituto de Biologia Experimental e Tecnológica, Avenida da República, Quinta-do-Marquês, Estação Agronómica Nacional, Apartado 12, 2781-901 Oeiras, \\ Portugal \\ d Department of Industrial Engineering, University of Salerno, Italy \\ e Instituto de Tecnologia Química e Biológica António Xavier, Universidade Nova de Lisboa, Av. Da República, 2780-157 Oeiras, Portugal \\ ${ }^{f}$ ProdAl Scarl, Competence Center on Agro-Food Productions, University of Salerno, Italy \\ ${ }^{\mathrm{g}}$ International Iberian Nanotechnology Laboratory, Av. Mestre José Veiga s/n, 4715-330 Braga, Portugal
}

\section{A R T I C L E I N F O}

\section{Keywords:}

Layer-by-layer

Polyelectrolytes

Multilayer nanoemulsions

Lipid digestion

Bioaccessibility and cytotoxicity

\begin{abstract}
A B S T R A C T
Nanoemulsions can be used to improve the bioaccessibility of lipophilic bioactive compounds, such as curcumin, being their behaviour highly influenced by their interfacial properties. The effect of chitosan and alginate layers' deposition on curcumin nanoemulsions' behaviour during in vitro digestion was evaluated using a dynamic gastrointestinal system. Results showed that polyelectrolyte layers' deposition improved curcumin antioxidant capacity during in vitro digestion. In addition, multilayer nanoemulsions showed a better control of the rate and extent of lipid digestibility by decreasing free fatty acids release, compared to uncoated nanoemulsions. However, a lower curcumin bioaccessibility was observed for multilayer nanoemulsions. Although cytotoxicity assays revealed that both nanosystems are toxic due to the use of sodium dodecyl sulphate (SDS), nanosystems were 3.3-fold less toxic than SDS itself.

This study showed that multilayer nanoemulsions could be used to increase satiety by retarding lipid digestion, which can be important for functional foods development for combating obesity.
\end{abstract}

\section{Introduction}

Consumers' demands for new and healthier foods are encouraging the food industry to seek for new strategies to fortify food products with bioactive compounds, turning foods into products that promote health and wellness (Cerqueira et al., 2013; Silva, Cerqueira, \& Vicente, 2012, 2015b). Some of these bioactive compounds are lipophilic often resulting in low bioavailability, whereas some are $\mathrm{pH}$ - and temperaturesensitive, being prone to oxidative and chemical degradation (Guttoff, Saberi, \& McClements, 2015; Mayer, Weiss, \& McClements, 2013; McClements, 2015; Zou et al., 2015). Lipid-based delivery systems can be designed to encapsulate, protect and control/trigger the release of bioactive compounds at specific locations within the gastrointestinal (GI) tract. Also, they can control the digestion of lipophilic bioactive compounds in the GI tract, while improving their bioavailability (Li et al., 2010; McClements \& Li, 2010; Sun et al., 2015). In particular, nanoemulsions can inhibit bioactive compounds' chemical and oxidative degradation, their large surface area can enhance lipid digestibility rates, improve the release of bioactive compounds, promote the faster formation of mixed micelles, while enhancing the bioactive compounds' permeability across the mucus layer and epithelium cells (Cerqueira et al., 2014; Sun et al., 2015; Ting, Jiang, Ho, \& Huang, 2014). Nonetheless, nanoemulsions present some drawbacks and their stability can be influenced by their behavior towards dehydration, temperature changes (e.g. heating, chilling and freezing-thawing) and passage through the GI tract (Cerqueira et al., 2014; Silva, Cerqueira, \& Vicente, 2015a). Multilayer nanoemulsions can be used as a strategy to improve the physical stability of nanoemulsions to environmental conditions

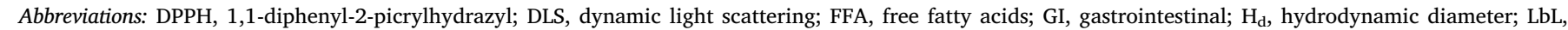

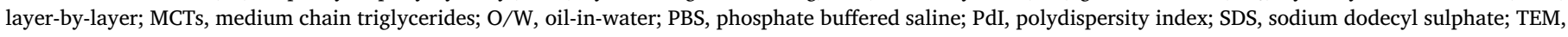
transmission electron microscopy; Zp, zeta potential

* Corresponding author at: Centre of Biological Engineering, University of Minho, 4710-057 Braga, Portugal.

E-mail address: anapinheiro@deb.uminho.pt (A.C. Pinheiro). 
such as $\mathrm{pH}$, ionic strength, heating, chilling or freeze-drying cycles, while controlling lipids' digestibility and release of bioactive compounds in response to specific environmental triggers (Acevedo-Fani, Soliva-Fortuny, \& Martín-Belloso, 2017). They can be produced using the layer-by-layer (LbL) technique, based on the deposition of charged polyelectrolytes onto oppositely charged lipid droplets (Acevedo-Fani, Silva, Soliva-Fortuny, Martín-Belloso, \& Vicente, 2017; Pinheiro, Coimbra, \& Vicente, 2016). Multilayer nanoemulsions' characteristics are known for being largely influenced by the properties of the outer polyelectrolyte layer, such as molecular weight, charge density, ionic composition and $\mathrm{pK}_{\mathrm{a}}$. However, the functional properties can be designed according to the type of polyelectrolyte, sequence of the polyelectrolyte layers, number of layers and the conditions to which the solutions are subjected during the construction of the system (Li et al., 2010).

The proper selection of the lipid nanosystem should be based on the final application. It is known that the large surface area of nanoemulsions allows the acceleration of the chemical reactions occurring at the oil-water interface such hydrolysis by lipases. Therefore, nanoemulsions' capacity to increase the rate and extent of lipids digestion, make them interesting for addressing human disorders that inhibit lipid digestion or absorption (Troncoso, Aguilera, \& McClements, 2012). On the contrary, changing the interfacial properties through the deposition of polyelectrolyte layers may help controlling lipids' digestibility by enhancing the coating integrity, preventing lipase and other enzymes from reaching the encapsulated lipids (McClements \& Li, 2010; Troncoso et al., 2012). By slowing down the digestibility rate of lipids, it is possible to stimulate ileal brake mechanism responsible for regulating hunger, satiety and satiation, thereby reducing the caloric intake of food products (Li et al., 2010; Maljaars, Peters, Haddeman, \& Masclee, 2009).

Therefore, understanding of the behavior of lipid-based nanosystems within the GI tract is of the highest importance for the development of lipid nanosystems with tailored physiological attributes, such as satiety enhancement, improved bioavailability or reduced fat absorption (Liu, Ma, Zhang, Gao, \& Julian McClements, 2017). With this view, the main purpose of this study was to evaluate the influence of the interfacial composition on the behavior of lipid-based nanosystems under in vitro GI conditions. To perform this evaluation, curcumin, a lipophilic bioactive compound with numerous beneficial effects on human health but a very low bioavailability, have been encapsulated in nanoemulsions. Nanoemulsions were produced using medium chain triglycerides (MCTs) as oil phase and SDS, as a anionic emulsifier. These nanoemulsions have been coated with oppositely charged biopolymers: alginate and chitosan, forming multilayer nanoemulsions. A dynamic GI model, comprising the simulation of stomach, duodenum, jejunum and ileum, was used in this study once it allows a more realistic simulation of the complex physicochemical and physiological processes that occur within the human GI tract. Also, the cytotoxicity of the nanosystems was evaluated using CaCo-2 cell line.

\section{Materials and methods}

\subsection{Materials}

Neobee 1053 MCTs, composed by caprylic/capric triglyceride oil with a fatty acid distribution of $55 \%$ of C8:0 and $44 \%$ of C10:0, was kindly provided by Stepan (The Netherlands) and was used without further purification. SDS, curcumin $(M w=368.38 \mathrm{Da}), 1,1$-diphenyl-2picrylhydrazyl (DPPH), pepsin from porcine gastric mucosa (600 $\left.\mathrm{U} \cdot \mathrm{mL}^{-1}\right)$, lipase from porcine pancreas $\left(40 \mathrm{U} \cdot \mathrm{mL}^{-1}\right)$, pancreatin from porcine pancreas $(8 \times$ USP), bile extract porcine and the salts used for preparing the gastric and small intestinal electrolyte solutions, hydrochloric acid, sodium bicarbonate, Nile Red 9-diethylamino-5H-benzo $[\alpha]$ phenoxazine-5-one and dimethyl sulfoxide were purchased from Sigma-Aldrich (St Louis, MO, USA). Chitosan (deacetylation degree $\geq 95 \%$ ) was purchased from Golden-Shell Biochemical CO., LTD (Zhejiang, China) and sodium alginate with $M w \approx 15,900 \mathrm{Da}$ and viscosity $\approx 200 \mathrm{cp}$ ( $1 \%$ aqueous solution with Brookfield Model $\mathrm{LV}^{-1} \mathrm{~s}^{-1} \mathrm{rpm}$ at $25^{\circ} \mathrm{C}$ ) from Manutex RSX, Kelco 104 International, Ltd. (Portugal). Lactic acid (90\%) was purchased from Acros Organics (Geel, Belgium). Sodium hydroxide and phenolphthalein were obtained from Panreac (Barcelona, Spain). Chloroform was obtained from Fisher Scientific (NJ, USA) and acetone from Fisher Chemical (Loughborough, UK). All cell culture media and supplements, namely RPMI 1640, Fetal Bovine Serum (FBS), Penicillin-Streptomycin (PS) and trypsin/EDTA, were obtained from Invitrogen (Paisley, UK). For cytotoxicity experiments phosphate buffered saline (PBS) powder was purchased from Sigma-Aldrich (St. Louis, USA) and CellTiter $96^{\circledR}$ AQueous One Solution Cell Proliferation Assay was obtained from Promega (Wisconsin, USA). Human colon carcinoma Caco-2 cells were purchased from Deutsche Sammlung von Mikroorganismen und Zellkulturen (DSMZ, Braunschweig, Germany). Distilled water (Milli-Q apparatus, Millipore Corp., Bedford, MA, USA) was used to prepare all solutions.

\subsection{Experimental procedures}

\subsubsection{Preparation of curcumin nanosystems}

2.2.1.1. Curcumin nanoemulsions. Oil-in-water $(\mathrm{O} / \mathrm{W})$ nanoemulsions were prepared according to a previous work (Silva et al., 2015b), with slight modifications. Briefly, $0.1 \%(\mathrm{w} / \mathrm{w})$ of curcumin was solubilized at $90^{\circ} \mathrm{C}$ in MCTs during $30 \mathrm{~min}$. The oily phase was then added to an aqueous phase containing $1 \%(\mathrm{w} / \mathrm{w})$ of SDS in distilled water. An oil-to-aqueous phase volume ratio of 1:9 was used. The nanoemulsions were pre-mixed during $2 \mathrm{~min}$ at $83.3 \mathrm{~s}^{-1}$ using an UltraTurrax homogenizer ( $\mathrm{T} 25$, Ika-Werke, Germany) followed by 20 cycles of homogenization through a high-pressure homogenizer equipped with a zirconia nozzle (Z4 nozzle) with $100 \mu \mathrm{m}$ of orifice (Nano DeBEE, BEE International, USA) at 15,000 Psi (103 MPa).

2.2.1.2. Curcumin multilayer nanoemulsions. Multilayer nanoemulsions were formed through adsorption of consecutive deposition of layers of polyelectrolytes onto the curcumin nanoemulsions using the LbL electrostatic deposition technique. The saturation method was applied, i.e. the layers were constructed by subsequent adsorption of polyelectrolytes from their solutions without the intermediate rinsing step. Therefore, an optimization step was conducted, in which different polyelectrolytes' concentrations (ranging from 0.01 to $0.1 \% \mathrm{w} / \mathrm{w}$ ) were tested. The concentration at which the nanoemulsions are completely coated by the polyelectrolyte layer and there is no significant excess of polyelectrolyte in solution (i.e. optimum polyelectrolytes' concentration) was assessed. These concentrations have been chosen based on particle size and zeta potential measurements, in accordance with other authors (Pinheiro et al., 2016). Briefly, constant values of zeta potential with increasing polyelectrolyte concentrations suggest that the nanoemulsions became saturated with the polyelectrolyte and also, polyelectrolyte concentrations at which low particle sizes are obtained suggest that nanoemulsions are not susceptible to droplet aggregation due to the strong electrostatic repulsion between the droplets and to the saturation of the droplets surfaces with the polyelectrolyte. Concentrations of $0.04 \%, 0.04 \%$ and $0.02 \%(w / w)$ for the build-up of the 1st (chitosan), 2nd (alginate) and 3rd (chitosan) layers were selected to construct the multilayer nanoemulsions. Briefly, anionic curcumin nanoemulsions were coated with alternating layers of positively charged chitosan solution (dissolved in 1\% lactic acid) at $\mathrm{pH}$ 3 , and negatively charged sodium alginate solution (dissolved in distilled water) at $\mathrm{pH} 7$ (volume ratio of 1:1, respectively) until the desired number of biopolymer layers was achieved (i.e. until obtaining the chitosan/alginate/chitosan/SDS-stabilized multilayer nanoemulsions). Polyelectrolyte solutions were used at the $\mathrm{pH}$ values where the polyelectrolytes were strongly charged and added dropwise with a syringe pump (NE-1000, New Era Pump Systems, Inc., USA) to 
fresh curcumin nanoemulsions, under stirring for $15 \mathrm{~min}$.

\subsubsection{Nanosystems size measurements}

The particle size distribution and polydispersity index $(P d I)$ of nanoemulsions and multilayer nanoemulsions were determined using Dynamic Light Scattering (DLS) (Zetasizer Nano ZS-90, Malvern Instruments, Worcestershire, UK). Nanoemulsion samples were diluted $10 \times$ in distilled water at room temperature. Data were reported as the mean droplet diameter (hydrodynamic diameter, $H_{d}$ ). $P d I$ is a dimensionless and indicates the heterogeneity (monodisperse or polydisperse) of particles' size in a mixture (Malvern, 2011). Each sample was analysed in a disposable polystyrene cell (DTS0012, Malvern Instruments). The measurements were performed in duplicate, with three readings for each of them. The results are given as the average \pm standard deviation of the six values obtained (Rao \& McClements, 2013; Silva et al., 2011).

\subsubsection{Nanosystems charge measurements}

The droplet charge (zeta potential, $Z p$ ) of the nanoemulsions and multilayer nanoemulsions was determined using a particle micro-electrophoresis instrument (Zetasizer Nano ZS-90, Malvern Instruments, Worcestershire, UK). Samples were diluted $100 \times$ in distilled water prior to measurements in order to avoid multiple scattering effects at ambient temperature and the diluted emulsions were placed into disposable capillary cells (DTS 1060, Malvern Instruments) (Ozturk, Argin, Ozilgen, \& McClements, 2014; Rao \& McClements, 2013).

\subsubsection{Nanosystems stability and curcumin release at GI conditions}

The stability of curcumin nanosystems under GI environmental conditions was investigated using the dialysis method, in accordance with other authors (Pinheiro et al., 2015). $2 \mathrm{~mL}$ of aqueous curcumin nanosystems were added into a dialysis membrane (molecular weight cut-off $15 \mathrm{kDa}$; Cellu-Sep H1, Membrane filtration products, USA). The sealed dialysis membrane was then placed into $50 \mathrm{~mL}$ of buffer solution (phosphate buffer, PBS, for $\mathrm{pH} 7.4$ and $\mathrm{KCl}-\mathrm{HCl}$ buffer for $\mathrm{pH} 2$ ) under magnetic stirring at $37^{\circ} \mathrm{C}$. At appropriate time intervals, $0.5 \mathrm{~mL}$ of supernatant were taken and $0.5 \mathrm{~mL}$ of fresh release medium (i.e. PBS or $\mathrm{KCl}-\mathrm{HCl}$ buffer) was added to keep the volume of the medium constant. The stability of the nanosystems and the released amount of curcumin from the nanosystems was evaluated by measuring the $H_{d}$ after $54 \mathrm{~h}$ and the absorbance at $425 \mathrm{~nm}$, maximum absorbance peak (Elisa Biotech Synergy HT, Biotek, USA), respectively. All tests were run at least in triplicate.

\subsubsection{In vitro digestion}

2.2.5.1. Dynamic GI model. A dynamic GI model was used for the in vitro digestion experiments, according to Pinheiro et al. (2016). This model simulates the main events that occur during digestion and consists of four compartments simulating the stomach, duodenum, jejunum and ileum. Each compartment consists of two connected glass reactors with a flexible wall inside and water is pumped around the flexible walls to maintain the temperature at $37^{\circ} \mathrm{C}$ and to enable the simulation of the peristaltic movements (by the alternate compression and relaxation of the flexible walls). The changes in water pressure are achieved by peristaltic pumps, which alter the flow direction according to the time controlling devices connected to them. The compartments are connected by silicone tubes and, at a predefined time, a constant volume of chyme is transferred. All compartments are equipped with $\mathrm{pH}$ electrodes and $\mathrm{pH}$ values are controlled by the secretion of $\mathrm{HCl}$ $\left(1 \mathrm{~mol} \cdot \mathrm{L}^{-1}\right)$ into the stomach and $\mathrm{NaHCO}_{3}\left(1 \mathrm{~mol} \cdot \mathrm{L}^{-1}\right)$ into the intestinal compartments. The gastric and intestinal secretions are added via syringe pumps at pre-set flow rates. The jejunum and ileum compartments are connected with polystyrene hollow-fibre devices with molecular weight cut-offs of $0.05 \mu \mathrm{m}$ (SpectrumLabs Minikros ${ }^{\circledR}$, M20S-100-01P, USA) to absorb digestion products and water from the chyme and to modify electrolyte and bile salts concentration of the chyme (Pinheiro et al., 2016; Reis et al., 2008).

It should be noted that, although at the mouth stage there may be changes in nanoemulsions' size and interfacial characteristics, influencing their fate in the GI tract (McClements \& Xiao, 2012), this phase was not included because the sample is liquid (and therefore the mastication is not relevant and the residence time in the mouth is very low) and does not contain starch (i.e. the primary enzyme present in saliva, amylase, would not act) (Pinheiro et al., 2016).

2.2.5.2. Experimental conditions. In vitro digestion was performed as described by other authors (Pinheiro et al., 2016; Reis et al., 2008) with minor modifications. A volume of $40 \mathrm{~mL}$ of curcumin and curcuminloaded nanosystems (i.e. nanoemulsions and multilayer nanoemulsions) was introduced into the dynamic GI system (gastric compartment) and run for a total of $5 \mathrm{~h}$, simulating the average physiological conditions of GI tract by the continuous addition of gastric, duodenal, jejunal and ileal secretions. Gastric secretion consisted of pepsin and lipase dissolved in a gastric electrolyte solution $\left(\mathrm{NaCl} 4.8 \mathrm{~g} \cdot \mathrm{L}^{-1}, \mathrm{KCl}\right.$ $2.2 \mathrm{~g} \cdot \mathrm{L}^{-1}, \mathrm{CaCl}_{2} 0.22 \mathrm{~g} \cdot \mathrm{L}^{-1}$ and $\mathrm{NaHCO}_{3} 1.5 \mathrm{~g} \cdot \mathrm{L}^{-1}$ ), secreted at a flow rate of $0.33 \mathrm{~mL} \cdot \mathrm{min}^{-1}$. The $\mathrm{pH}$ was controlled to follow a predetermined curve (from 4.8 at $t=0$ to 1.7 at $t=120 \mathrm{~min}$ ) by secreting $\mathrm{HCl}\left(1 \mathrm{~mol} \cdot \mathrm{L}^{-1}\right)$. The duodenal secretion consisted of a mixture of $4 \%(\mathrm{w} / \mathrm{v})$ porcine bile extract, $7 \%(\mathrm{w} / \mathrm{v})$ pancreatin solution and small intestinal electrolyte solution (SIES) $\left(\mathrm{NaCl} 5 \mathrm{~g} \cdot \mathrm{L}^{-1}\right.$, $\mathrm{KCl} \quad 0.6 \mathrm{~g} \cdot \mathrm{L}^{-1}, \mathrm{CaCl}_{2} \quad 0.25 \mathrm{~g} \cdot \mathrm{L}^{-1}$ ) secreted at a flow rate of $0.66 \mathrm{~mL} \cdot \mathrm{min}^{-1}$. The jejunal secretion fluid consisted of SIES containing $10 \%(\mathrm{v} / \mathrm{v})$ porcine bile extract solution at a flow rate of $2.13 \mathrm{~mL} \cdot \mathrm{min}^{-1}$. The ileal secretion fluid consisted of SIES at a flow rate of $2.0 \mathrm{~mL} \cdot \mathrm{min}^{--1}$. The $\mathrm{pH}$ in the different compartments of small intestine was controlled by the addition of $1 \mathrm{~mol} \cdot \mathrm{L}^{-1} \mathrm{NaHCO}_{3}$ solution to set points of 6.5, 6.8 and 7.2 for simulated duodenum, jejunum and ileum, respectively. During in vitro digestion, samples were directly collected from the lumen of the different compartments (stomach sample collected at $90 \mathrm{~min}$ of gastric digestion and duodenum sample collected at $120 \mathrm{~min}$ of duodenal digestion), from jejunal and ileal filtrates (i.e. fractions absorbed at jejunum and ileum compartments, respectively, collected at the end of the experiment) and from the ileal delivery (i.e. fraction that was not absorbed in the small intestine, collected at the end of the experiment). The jejunal and ileal filtrates were used to determine the bioaccessibility of curcumin. The samples were analysed in terms of $H_{d}, Z p$ and amount of released free fatty acids (FFA). Both curcumin nanosystems were tested in the dynamic GI model at least in triplicate.

\subsubsection{Morphological characterization}

Nanosystems' morphology was evaluated by transmission electron microscopy (TEM) (EM 902A, ZEISS, Germany) operating at $80 \mathrm{kV}$. TEM samples were prepared by depositing the nanosystems on a carbon-coated copper grid, and negatively stained with $1 \%(\mathrm{w} / \mathrm{v})$ uranyl acetate for observation. Samples were air-dried prior to being analysed. Also, the oil droplets in the nanosystems were studied using an epifluorescence microscope (BX51 OLYMPUS, Tokyo, Japan) with a $\times 100$ oil immersion objective lens. Samples were stained with Nile Red (9-diethylamino-5H-benzo[ $\alpha$ ]phenoxazine-5-one, $0.25 \mathrm{mg} \cdot \mathrm{mL}^{-1}$ in dimethyl sulfoxide, 1:10 (dye:sample, v/v), which enabled the oil droplets to become visible. Slides were prepared by taking $10 \mu \mathrm{L}$ of the stained nanosystems' solution and placing in a glass microscope slide and covering with a glass cover slip.

\subsubsection{Free fatty acids release}

The extent of lipolysis was evaluated by determining the amount of FFA released from curcumin nanoemulsions using a titration method, selected due to their low complexity and time demand (Pinsirodom \& Parkin, 2005). Briefly, $5 \mathrm{~mL}$ of jejunal filtrate, ileal filtrate and ileal delivery samples were collected and $10 \mathrm{~mL}$ of acetone were added to quench the enzymes' activity, then three drops of $1 \%(\mathrm{w} / \mathrm{v})$ of 
phenolphthalein were added as an indicator. A direct titration using $0.1 \mathrm{~mol} \cdot \mathrm{L}^{-1} \mathrm{NaOH}$ was performed and the volume of $\mathrm{NaOH}$ added until the titration end point was determined and used to calculate the concentration of FFA produced by lipolysis. Therefore, the percentage of FFA released was calculated from the number of moles of $\mathrm{NaOH}$ required to neutralize the FFA divided by the number of moles of FFA that could be produced from triglycerides if they were all digested (assuming 2 FFA produced per 1 triacylglycerol molecule) ( $\mathrm{Li}, \mathrm{Hu}, \mathrm{Du}$, Xiao, \& McClements, 2011):

$\% F F A=100 \times\left(\frac{v_{\mathrm{NaOH}} \times m_{\mathrm{NaOH}} \times M_{\text {lipid }}}{w_{\text {lipid }} \times 2}\right)$

where $v_{\mathrm{NaOH}}$ is the volume of sodium hydroxide required to neutralize the FFA generated (in $\mathrm{mL}$ ), $m_{\mathrm{NaOH}}$ is the molarity of the sodium hydroxide used (in mol. $\mathrm{L}^{-1}$ ), $w_{\text {lipids }}$ is the total weight of MCTs oil initially present and $M_{\text {lipid }}$ is the molecular weight of the MCTs oil (based on their average fatty acid composition, the molecular weight of MCTs oil was considered to be $503 \mathrm{~g} \cdot \mathrm{mol}^{-1}$ ).

\subsubsection{Curcumin bioaccessibility}

It was assumed that the fraction of the curcumin present in the initial nanoemulsions/multilayer nanoemulsions that ended up in the micelle phase was a measure of curcumin bioaccessibility (Ahmed, Li, McClements, \& Xiao, 2012; Pinheiro et al., 2016) and that the mixed micelles that contained the bioaccessible curcumin fraction were able to pass the hollow-fibre membranes (i.e. corresponding to jejunal filtrate and ileal filtrate samples), while undigested emulsions were retained (Minekus et al., 2005; Pinheiro et al., 2016). Curcumin bioaccessibility was determined based on the methodology described by other authors (Ahmed et al., 2012; Pinheiro et al., 2016). Briefly, $5 \mathrm{~mL}$ of the sample (jejunal or ileal filtrate) were vortexed with $5 \mathrm{~mL}$ of chloroform, and then centrifuged (Sigma $4 \mathrm{~K} 15$, Germany) at $651 \mathrm{~g}$, at room temperature, for $10 \mathrm{~min}$. The bottom chloroform layer was collected and the extraction procedure was repeated with the top layer. The second bottom chloroform layer was added to the previously set aside chloroform layer, mixed, and analysed in a UV-VIS spectrophotometer (Elisa Biotech Synergy HT, Biotek, USA) at $425 \mathrm{~nm}$ (maximum absorbance peak of curcumin). Curcumin concentration was determined from a previously prepared calibration curve of absorbance versus curcumin concentration in chloroform.

\subsubsection{Antioxidant activity of curcumin}

Free-radical scavenging capacity of curcumin and curcumin nanosystems was analysed using DPPH test according to the method described by Pinheiro et al (2015), with some modifications. Briefly, $0.2 \mathrm{~mL}$ of ethanol and $0.3 \mathrm{~mL}$ of the curcumin dissolved in ethanol (concentrations ranging from 0.05 to $5.0 \mathrm{mg} \cdot \mathrm{mL}^{-1}$ ) or curcumin from the digested nanosystems were mixed in a $10 \mathrm{~mL}$ test tube with $2.5 \mathrm{~mL}$ of DPPH ( $60 \mu \mathrm{mol} \mathrm{L}^{-1}$ in ethanol), achieving a final volume of $3.0 \mathrm{~mL}$. For the antioxidant activity of curcumin during the digestion steps, nanosystems without curcumin were used as controls. The solution was kept at room temperature for $30 \mathrm{~min}$ and the absorbance was measured at $517 \mathrm{~nm}$ (Pinheiro et al., 2015; Rufino et al., 2007; Souza et al., 2012).

The DPPH scavenging effect was calculated as follow:

Scavenging effect $(\%)=\frac{A_{0}-\left(A_{s}-A_{b}\right)}{A_{0}} \times 100$

where $A_{0}$ is the absorbance at $517 \mathrm{~nm}$ of DPPH without sample, $A_{s}$ is the absorbance at $517 \mathrm{~nm}$ of sample and DPPH and $A_{b}$ is the absorbance at $517 \mathrm{~nm}$ of sample without DPPH. The absorbance measurements were performed in Elisa Biotech Synergy HT (Biotek, USA) (Pinheiro et al., 2015).

\subsubsection{Cell culture}

Caco-2 cell line, originally obtained from human colon adenocarcinoma, undergoes in a process of spontaneous differentiation that leads to the formation of a monolayer of cells, expressing several morphological and functional characteristics of the mature enterocyte (Sambuy et al., 2005). Caco-2 cells were routinely grown in a standard medium: RPMI 1640 supplemented with $10 \%$ (v/v) of inactivated FBS and $1 \%(\mathrm{v} / \mathrm{v})$ of PS. Stock cells were maintained as monolayers in $80 \mathrm{~cm}^{2}$ culture flasks. Cells were subcultured every week at a split ratio of 1 to 4 by treatment with trypsin/EDTA $(0.25 \%)$ and incubated at $37^{\circ} \mathrm{C}$ in a $5 \% \mathrm{CO}_{2}$ humidified atmosphere. For cytotoxicity experiments cells were used between passages 40 and 50 .

\subsubsection{Cytotoxicity assay}

Caco- 2 cells were harvested and seeded in 96-well plates at a density of $2 \times 10^{4}$ cells/well and the medium was changed every $48 \mathrm{~h}$. After cells reached confluence $(\sim 96 \mathrm{~h}), 100 \mu \mathrm{L}$ of nanoemulsions or multilayer nanoemulsions were added to cells in a concentration ranging between 0.15 and $4.75 \mu \mathrm{g}$ of curcumin $/ \mathrm{mL}$. Also, the components of the nanosystems (curcumin, SDS and chitosan) were tested for toxicity in Caco-2 cell line. Curcumin stock solution was prepared in pure ethanol while the SDS and chitosan stock solutions were prepared in distilled water, all at a final concentration of $4 \mathrm{mg} \cdot \mathrm{mL}^{-1}$. After $4 \mathrm{~h}$ of incubation at $37^{\circ} \mathrm{C}$ in a $5 \% \mathrm{CO}_{2}$ humidified atmosphere cells were rinsed twice with PBS to remove traces of samples and $100 \mu \mathrm{L}$ of a CellTiter $96^{\circledR}$ AQueous One Solution Cell Proliferation Assay reagent (MTS) previously diluted in RPMI 1640 medium was added to each well and left to react for $2 \mathrm{~h}$. MTS is bio-reduced by cells into a coloured formazan product that is soluble in tissue culture medium. The quantity of formazan produced was measured spectrophotometrically at $490 \mathrm{~nm}$ in a microplate reader (EPOCH, Bio-Tek, USA) and is directly proportional to the number of living cells in culture. Results were expressed in terms of percentage of cellular viability relative to a group control (cells only with RPMI medium). Experiments were performed in triplicate in three independent assays.

\subsection{Statistical procedures}

Data analyses were performed using Microsoft Windows Excel 2011, using the Tukey's Multiple Comparison Test with a confidence interval of $95 \%$ in GraphPad Prism 5 (GraphPad Software, Inc.) and using ANOVA in STATISTICA 7.0 (Statsoft, Tulsa, OK, USA).

\section{Results and discussion}

\subsection{Development and characterization of curcumin nanosystems}

\subsubsection{Curcumin nanosystems characteristics}

The process conditions used for the development of the curcumin nanoemulsions led to a final mean droplet diameter of $80.0 \pm 0.9 \mathrm{~nm}$, being particularly efficient for the development of small droplet sizes $(<100 \mathrm{~nm}) . \quad P d I$ and $Z p$ values were $0.177 \pm 0.009$ and $-65.8 \pm 5.8 \mathrm{mV}$, respectively.

Regarding multilayer nanoemulsions, a $H_{d}$ of $130 \pm 1.5 \mathrm{~nm}$, a $P d I$ of $0.237 \pm 0.004$ and a $Z p$ of $10.4 \pm 0.9 \mathrm{mV}$ were obtained. The concentration of the encapsulated curcumin within the nanosystems was $78 \pm 0.8 \mu \mathrm{g} \cdot \mathrm{mL}^{-1}$. Fig. 1 (initial) presents the TEM microphotographs of nanoemulsions and multilayer nanoemulsions, confirming the development of these nanosystems and validating the mean droplet diameters obtained by DLS.

\subsection{Evaluation of nanosystems behaviour under GI pH and temperature conditions}

The behaviour of the nanosystems was evaluated under GI pH and temperature conditions, i.e. $\mathrm{pH} 2$ and 7.4 at $37^{\circ} \mathrm{C}$. It was observed that at these $\mathrm{pH} /$ temperature conditions, both nanosystems were unable to release curcumin. This was confirmed by measuring the content of 


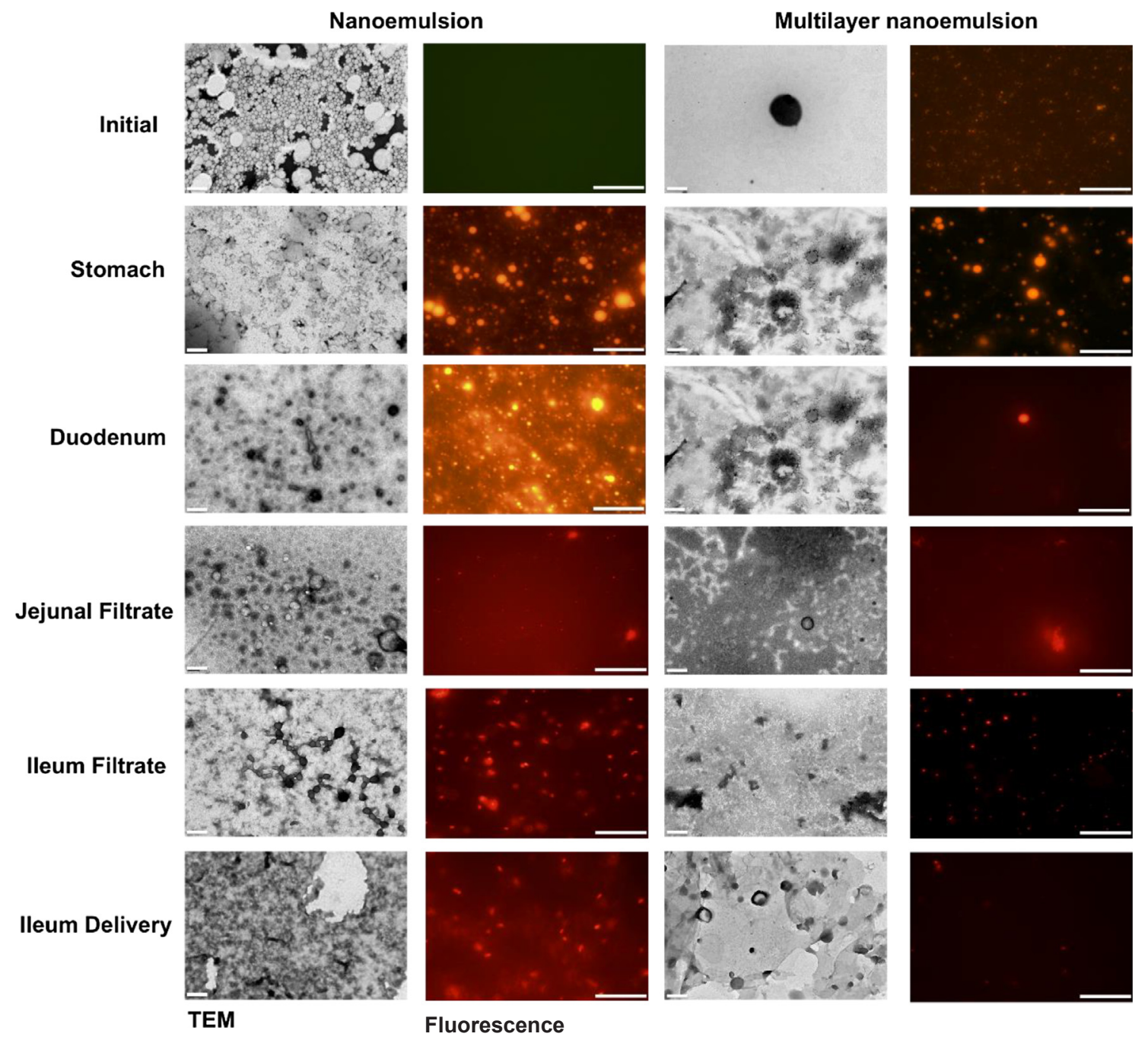

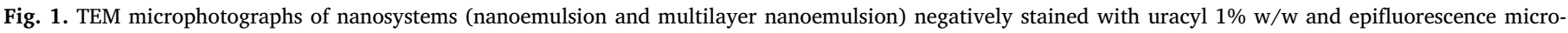

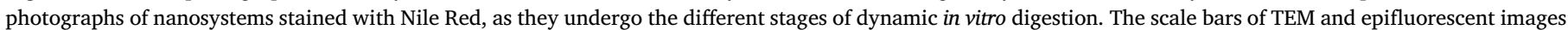
are $400 \mathrm{~nm}$ and $20 \mu \mathrm{m}$, respectively.

curcumin in the release media, which was below the detection limit of $0.01 \mu \mathrm{g} \cdot \mathrm{mL}^{-1}$, and by measuring the curcumin that remained encapsulated $\left(77.5 \pm 1.5 \mu \mathrm{g} \cdot \mathrm{mL}^{-1}\right)$, which did not show any significant variation with respect to the curcumin initially present within the nanosystems $\left(77.9 \pm 0.8 \mu \mathrm{g} \cdot \mathrm{mL}^{-1}\right)$. Regarding size stability, at $\mathrm{pH} 7.4$ the nanosystems showed the ability to maintain their initial size $(p>0.05)$, after $54 \mathrm{~h}$ of release assays, presenting $82.3 \pm 1.7 \mathrm{~nm}$ for nanoemulsions and $139.8 \pm 9.4 \mathrm{~nm}$ for multilayer nanoemulsions. At this $\mathrm{pH}$, above the $\mathrm{pK}_{\mathrm{a}}$ of chitosan $(\approx 6.5)$, the amino groups are entirely deprotonated and could contribute to loss of solubility of the chain segments (Vachoud, Zydowicz, \& Domard, 2000). It is also possible that chitosan layers held some positive charge at $\mathrm{pH}$ 7.4. In fact, previous works showed that when polyelectrolyte chains are entangled between oppositely charged polyelectrolytes, the $\mathrm{pK}_{\mathrm{a}}$ of the charged groups can considerably change, increasing the stability of multilayer nanoemulsions to $\mathrm{pH}$ changes (Burke \& Barrett, 2003a, 2003b; Li et al., 2010). At pH 2, the nanosystems presented signs of creaming and phase separation, being unstable at this $\mathrm{pH}$ after $54 \mathrm{~h}$ of release assays. At $\mathrm{pH}$ values below the $\mathrm{pK}_{\mathrm{a}}$ of the carboxylic acid groups present in alginate $(\approx 3.6)$ these groups are deprotonated, thereby the alginate layer could desorb from the droplets' surface, inducing phase separation (Harnsilawat, Pongsawatmanit, \& McClements, 2006; Li et al., 2010). The low solubility of curcumin in aqueous systems, reported to be $11 \mathrm{ng} \cdot \mathrm{mL}^{-1}$ could also explain the lack of curcumin released to both release media, since sink conditions towards curcumin were not established (Jelezova et al., 2015; Zhao et al., 2012). Nevertheless, this assay was only performed to understand the stability of developed nanosystems under the $\mathrm{pH}$ and temperature values used in the subsequent in vitro GI system.

\subsection{Dynamic in vitro digestion}

3.3.1. Influence of polyelectrolytes on the behaviour of nanosystems during in vitro digestion

The effect of the polyelectrolytes' layers in the nanosystem values of $H_{d}, P d I, Z p$ and morphology were evaluated at each stage of the dynamic in vitro digestion. As stated before, the initial droplet diameters were around $80 \mathrm{~nm}$ and $130 \mathrm{~nm}$ for the nanoemulsions and multilayer nanoemulsions, respectively. At the stomach stage, a slight increase of nanoemulsions $H_{d}$ was observed, from $80 \mathrm{~nm}$ to $104.1 \pm 5.9 \mathrm{~nm}$ (Fig. 2). On the contrary, a significant increase in the PdI was observed from 0.180 to $0.380 \pm 0.05$, which evidences the occurrence of coalescence phenomena, further confirmed by the epifluorescence microscopy (Fig. 1 - stomach). For the multilayer nanoemulsions, an increase of the $H_{d}$ to $214.9 \pm 27.6 \mathrm{~nm}$ was observed under gastric conditions. This increase associated with the increase of the PdI to $0.572 \pm 0.190$, reveals that the phenomena of coalescence occurred. This was confirmed by the epifluorescence microscopy (Fig. 1 - stomach) although 


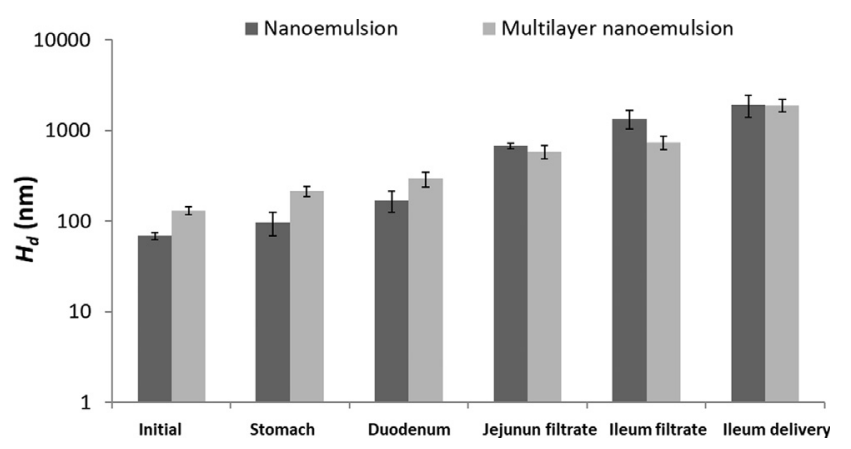

Fig. 2. Hydrodynamic diameter $\left(H_{d}\right)$ of the nanosystems (nanoemulsion and multilayer nanoemulsion) as they undergo the different stages of dynamic in vitro digestion. The results are presented as the mean values of triplicate experiments. For better reading the horizontal axis is on log scale.

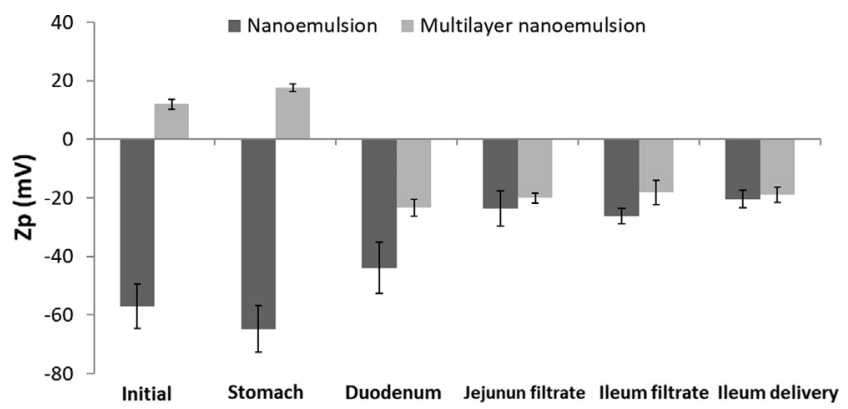

Fig. 3. Zeta potential values $(Z p)$ of the nanosystems (nanoemulsion and multilayer nanoemulsion) as they undergo the different stages of dynamic in vitro digestion. The results are presented as the mean values of triplicate experiments.

the TEM micrographs show that droplets in the nano-size range are still present. The behaviour of the multilayer nanoemulsions is related with the interfacial effect of the layers. One explanation could be the deprotonation of alginate under gastric conditions, which starts to desorb from the droplets surface inducing phase separation in this stage (Harnsilawat et al., 2006; Li et al., 2010). Also under gastric conditions, nanoemulsion droplets have a highly negative charge of $-64 \pm 8 \mathrm{mV}$ (Fig. 3), exhibiting a strong electrostatic repulsion between them, able to avoid droplets flocculation, coalescence and aggregation. In contrast, multilayer nanoemulsions present low $Z p$ values $(17.5 \pm 1.3 \mathrm{mV}$, Fig. 3), and despite of the electrical repulsion, the forces involved are not enough to completely inhibit the occurrence of the coalescence phenomena. The electrostatic attraction between alginate (inner layer) and chitosan (outer layer) is weakened due the partial loss of charges that alginate undergoes at acidic $\mathrm{pH}$ (below the alginate $\mathrm{pK}_{\mathrm{a}}$ ), leading to some aggregation of the particles that was visible through epifluorescence microscopy shown in Fig. 1 (Tokle, Lesmes, \& McClements, 2010; Tokle, Lesmes, Decker, \& McClements, 2012). The electrical charge of multilayer nanoemulsions becomes more positive in the stomach, which can be explained by various phenomena, such as: (i) the increase of the electrical charge of chitosan due to $\mathrm{pH}$ and ionic strength of the solutions, maintaining the electrostatic repulsion between polyelectrolytes and surfactant; (ii) adsorption of components from the gastric solution to the chitosan outer layer; or (iii) polyelectrolytes' displacement by the active materials present in the gastric solution (Hur, Decker, \& McClements, 2009). TEM micrographs show that multilayer nanoemulsions have particles within the nano-size range; this might be explained by the alginate layer retaining some negative charges, despite at these conditions their electrical charge should be nearly $0 \mathrm{mV}$. As referred before, when charged groups of polyelectrolytes are entangled between two or more oppositely charged polyelectrolytes, a change in the $\mathrm{pK}_{\mathrm{a}}$ values can occur, increasing the stability of multilayers to changes in $\mathrm{pH}$ (Burke \& Barrett, 2003a, 2003b; Li et al., 2010).

Under intestinal conditions, both nanosystems exhibited an increase of $H_{d}$ and $P d I$ values, possibly due to particle aggregation either by flocculation or coalescence of droplets (Fig. 2). At the duodenal stage, the $H_{d}$, increased to $168.5 \pm 44.1 \mathrm{~nm}$ and the $P d I$ was $0.42 \pm 0.12$ for the nanoemulsions with a $Z p$ value of $-44.1 \pm 8.8 \mathrm{mV}$. For multilayer nanoemulsions, the $H_{d}$ increased to $292.3 \pm 53.5 \mathrm{~nm}$, with a $P d I$ of $0.65 \pm 0.28$ and a $Z p$ of $-23.3 \pm 2.9 \mathrm{mV}$. The microscopic evaluation (Fig. 1 - duodenum) showed that at the duodenum stage, both nanosystems still exhibited droplets at the nano-scale, but at the same time exhibits droplets at the micro-scale, which confirms the wide droplet size distribution indicated by the $P d I$ value. The jejunal conditions further promoted the increase of the $H_{d}$ values of both nanosystems, to $681.2 \pm 47.6 \mathrm{~nm}$ and $586.9 \pm 101.8 \mathrm{~nm}$ for nanoemulsions and multilayer nanoemulsions, respectively. Ileal filtrate and ileal delivery exhibited higher mean droplet diameters than the jejunal filtrate. At these digestion fractions, $H_{d}$ values in the magnitude of 1-2 $\mu \mathrm{m}$ were observed (Fig. 2). However, TEM analyses showed that non-digested nanosystems were still present in the jejunum and ileum stages of the digestion; these can contribute to the high values of $P d I$ (higher than 0.5). The largest increase in the $H_{d}$ observed at small intestine conditions may be due to the fact that bile salts are able to displace surfactants and polyelectrolytes from the droplets' surface and lipase may induce the hydrolysis of the triacylglycerol molecules present into FFA, monoacyglycerides and/or diacylglycerides (Pinheiro et al., 2016). Also, this hydrolysis can generate structures such as micelles, vesicles or other colloidal structures (Mu \& Høy, 2004).

It was found that the electrical charges (expressed by the $Z p$ values) at these stages of the digestion decreased in the case of nanoemulsions and completely changed in the case of the multilayer nanoemulsions (from positive to negative charges), reaching a relatively constant value between $-25 \mathrm{mV}$ and $-20 \mathrm{mV}$ (Fig. 3). These changes of the droplets charge suggest that the bile salts or FFA adsorbed to the surface of the nanoemulsions or to the surface of the chitosan layer present in multilayer nanoemulsions, or that the presence of the bile salts or free fatty acids promoted the displacement of the surfactant and polyelectrolytes from the droplets surface (Klinkesorn \& Julian McClements, 2010; Salvia-Trujillo, Sun, Um, Park, \& McClements, 2015; Zou et al., 2015). From jejunum to ileum stages of the digestion there were no significant differences $(p>0.05)$ between the values of $Z p$ of both nanosystems.

\subsubsection{Influence of polyelectrolytes on lipids digestion}

The addition of polyelectrolyte layers to the curcumin nanoemulsions had a significant effect on the extent of lipid digestion, significantly reducing $(p<0.05)$ the overall FFA released (Fig. 4), achieving $\quad 71.3 \pm 3.5 \%$ and $52.3 \pm 10.6 \%$ for curcumin

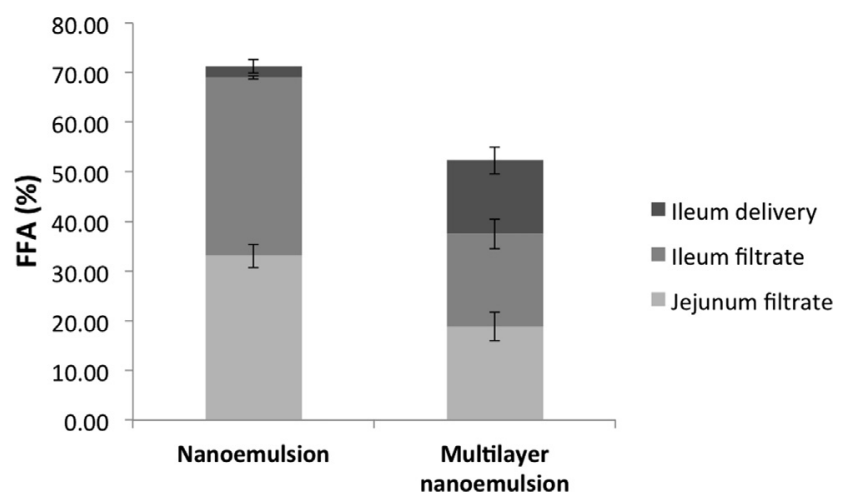

Fig. 4. Percentage of free fatty acids (FFA) released from the nanosystems (nanoemulsion and multilayer nanoemulsion) in the jejunum and ileum filtrate and ileum delivery fractions. The results are presented as the mean values of triplicate experiments. 
nanoemulsions and multilayer nanoemulsions, respectively. This suggests that the presence of the layers in the multilayer nanoemulsions delayed lipid digestion, slowing down the release rate of FFA. For both jejunal and ileal filtrate fractions, curcumin multilayer nanoemulsions lead to a significantly $(p<0.05)$ lower amount of FFA, when compared to curcumin nanoemulsions, being these results in agreement with previous studies (Pinheiro et al., 2016). A possible explanation for the decrease of the FFA release when using polyelectrolyte layers is the ability that bile salts have to form electrostatic complexes with the chitosan outer layer, reducing the digestibility of the lipids by sterically hindering the lipase (Klinkesorn \& Julian McClements, 2010; Klinkesorn \& McClements, 2009). Another possible explanation is that at this stage of the digestion, since the cationic functional groups of chitosan have a $\mathrm{pK}_{\mathrm{a}}$ value around $\mathrm{pH} 6.5$, chitosan could lose most of its charges and form large chitosan aggregates that would impede the access of lipase to the lipids (Zhang et al., 2015). Also, the presence of calcium ions, that have a strong ability for binding with alginate, may slow down the digestion of the FFA (Hu, Li, Decker, \& McClements, 2010).

It is also interesting to notice that amount of FFA present in the ileal delivery fraction is significantly higher for multilayer nanoemulsions comparing to nanoemulsions, which means that the coating addition, besides slowing down the release of FFA, also contributed to hinder their absorption.

These results suggest that the addition of chitosan and alginate layers surrounding nanoemulsions may be useful to control the rate of lipid digestion and FFA adsorption within the GI tract. These findings could be important for the design of structures that are able to decrease the rate of lipids digestion, increasing the amount of undigested food at ileum, which can encourage the ileal brake mechanism responsible for the regulation of hunger, satiety and satiation, while also reducing the caloric content of food products (Li et al., 2010; McClements \& Li, 2010; McClements, 2010).

\subsubsection{Influence of polyelectrolytes on curcumin bioaccessibility}

Higher bioaccessibility values were observed for nanoemulsions $(43.64 \pm 6.36 \%)$ when compared multilayer nanoemulsions $(26.98 \pm 3.99 \%)$ Fig. 5. One possible explanation for this result can be the fact that polyelectrolyte layers were efficient in protecting the release of curcumin from the multilayer nanoemulsions, leading to undigested nanosystems able to retain curcumin; another explanation is the presence of less mixed micelles, which are necessary to solubilise the curcumin (Salvia-Trujillo, Qian, Martín-Belloso, \& McClements, 2013; Zhang et al., 2015).

For both nanosystems, the determined amount of curcumin was similar between the jejunal and ileum filtrates. However, the

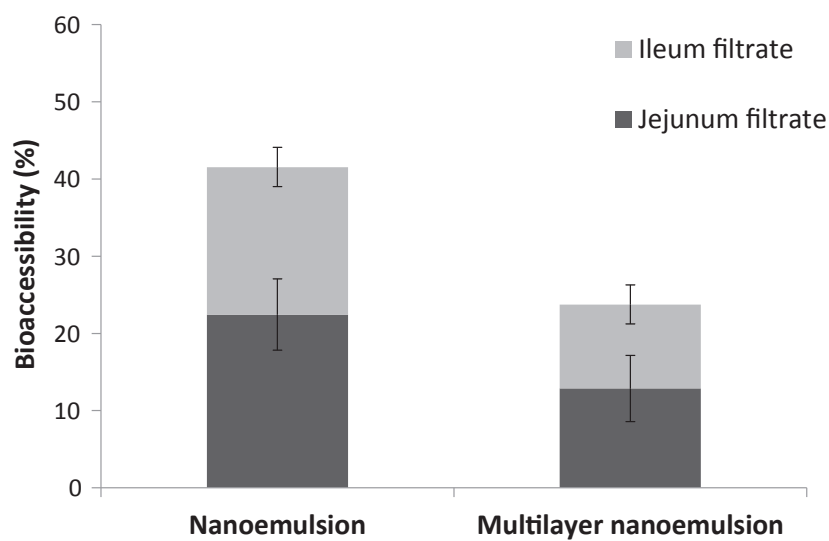

Fig. 5. Percentage of bioaccessibility of curcumin from nanosystems (nanoemulsion and multilayer nanoemulsion) in jejunum and ileum filtrate fractions. The results are presented as the mean values of triplicate experiments.

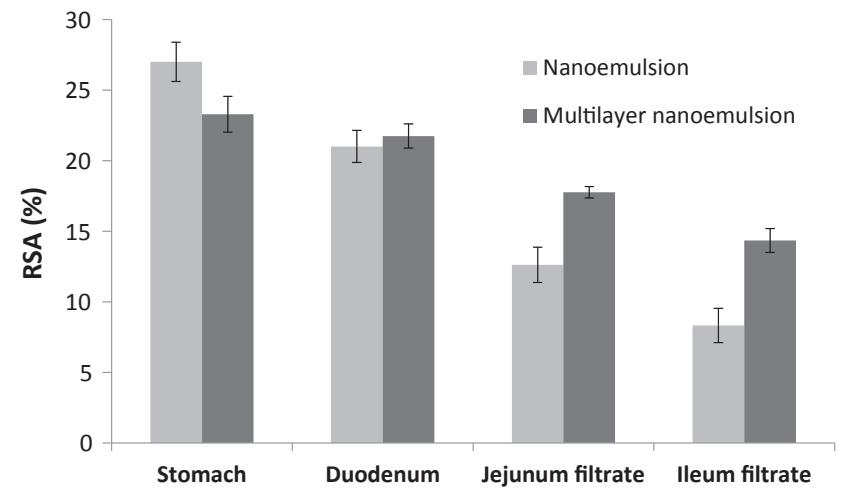

Fig. 6. Antioxidant capacity of curcumin nanosystems expressed in percentage of the radical scavenging activity (RSA) as the nanosystems undergo the different stages of dynamic in vitro digestion. The results are presented as the mean values of triplicate experiments.

nanoemulsions presented significantly higher concentrations of curcumin at both jejunal and ileum filtrate. These results are in agreement with FFA release results (Fig. 4), A crucial step for the bioavailability of bioactive compounds is the access of lipases to the lipid phase where it is dissolved, therefore, the release of FFA in the jejunal and ileal compartments is related to curcumin bioaccessibility observed in these samples. In fact, the digestion products (i.e. FFA) can be part of the mixed micelles, increasing the solubility of curcumin and thus increasing the bioaccessibility in the small intestine (Pinheiro et al., 2016; Porter, Trevaskis, \& Charman, 2007).

The bioaccessibility of free curcumin solubilised in MCTs was also evaluated (data not shown), achieving only $0.15 \pm 0.01 \%$ at the jejunal filtrate, while there was no evidence of curcumin at the ileal filtrate fraction. The reasons for the low bioaccessibility of the free curcumin in MCTs can be attributed to: (i) poor solubility of curcumin in aqueous solutions, (ii) the lack of mixed micelles for the solubilisation of curcumin and (iii) curcumin instability (i.e. degradation) during in vitro digestion.

\subsubsection{Influence of polyelectrolytes in the antioxidant activity of curcumin}

Fig. 6 shows curcumin antioxidant activity, determined as the radical scavenging activity of curcumin. Results showed that curcumin radical scavenging activity decreased during in vitro digestion, from $27.01 \pm 1.39 \%$ in stomach to $8.32 \pm 1.21 \%$ for the nanoemulsions in the ileum filtrate and from $23.30 \pm 1.27 \%$ in the stomach to $14.35 \pm 0.84 \%$ in the ileum filtrate for multilayer nanoemulsions. The decrease of the antioxidant activity of curcumin could be explained by the degradation of curcumin during digestion. Curcumin is prone to chemical degradation at neutral $\mathrm{pH}$ and above, resulting in the formation of different reaction products, as trans-6-(4'-hydroxy-3'-methoxyphenyl)-2,4-dioxo-5-hexanal, ferulic acid, feruloylmethane, and vanillin (Zou et al., 2015). Also other factors, such as ionic strength, enzymatic degradation, mechanistic motilities or free radicals (e.g. hydroxyl radicals), can theoretically contribute to the degradation of curcumin (Ting et al., 2014). Fig. 6 shows that for jejunal and ileal filtrate samples, the radical scavenging activity is significantly lower $(p<0.05)$ for the nanoemulsions, which might be explained by a higher degradation of curcumin during digestion in this sample. This result suggests that the polyelectrolyte layers are more effective in the protection of curcumin. This could be explained by the fact that polyelectrolyte layers are sterically hindering curcumin from enzymatic or free radicals degradation, nonetheless it may also be explained by the higher size and lower surface area of the multilayer nanoemulsions: if there is a lower surface area in contact with the surrounding aqueous phase, less curcumin would be in direct contact with any catalysts that could trigger curcumin degradation (Zou et al., 2015). However, once the nanosystems present different interfacial properties, further studies 
Table 1

$I C_{50}$ values of nanoemulsions, multilayer nanoemulsions, sodium dodecyl sulfate (SDS), curcumin and chitosan.

\begin{tabular}{lll}
\hline Sample & $\mu \mathrm{g} \mathrm{mL}^{-1}$ & $\mu \mathrm{g} \mathrm{SDS} \mathrm{mL}^{-1}$ \\
\hline Nanoemulsion & $1.125 \pm 0.028$ & $112.48 \pm 2.81$ \\
Multilayer nanoemulsion & $1.128 \pm 0.079$ & $112.81 \pm 7.89$ \\
SDS & $34.30 \pm 2.18$ & $34.30 \pm 2.18$ \\
Curcumin & $>4.75$ & - \\
Chitosan & $>31.25$ & - \\
\hline
\end{tabular}

would be needed to confirm the size contribution for these results.

\subsection{Cytotoxicity assay}

The evaluation of the nanosystems' cytotoxicity is of utmost importance for safety reasons, if the ultimate objective is the introduction of these nanosystems into food products. As a preliminary test, the cytotoxicity of original nanosystems (i.e. before digestion) has been evaluated in order to take also into account their nano-size (i.e. after digestion their size significantly increased).

Although curcumin did not present any intrinsic cytotoxicity ( $>4.75 \mu \mathrm{g}_{\text {curcumin }} \cdot \mathrm{mL}^{-1}$ ), the results showed that nanoemulsions and multilayer nanoemulsions were toxic for Caco-2 cells after $4 \mathrm{~h}$ of incubation, within the studied concentration range, with $I C_{50}$ values of $1.125 \pm 0.028 \quad \mu g_{\text {nanosystems }} \cdot \mathrm{mL}^{-1}$ and $1.128 \pm 0.079$ $\mu \mathrm{g}_{\text {nanosystems }} \cdot \mathrm{mL}^{-1}$, respectively, equivalent to $0.855 \pm 0.02$ $\mu \mathrm{g}_{\text {curcumin }} \cdot \mathrm{mL}^{-1}$ and $0.858 \pm 0.06 \mu \mathrm{g}_{\text {curcumin }} \cdot \mathrm{mL}^{-1}$ for the nanoemulsions and multilayer nanoemulsion, respectively (Table 1 ). In order to understand the cytotoxicity of the nanosystems, the $I C_{50}$ values for chitosan and SDS were determined. Chitosan did not show any cytotoxicity in the range of concentrations tested, relatively to the control $(100 \%$ of cell viability) after $4 \mathrm{~h}$ of incubation ( $>31.25$ of $\mu \mathrm{g}_{\text {chitosan }} \cdot \mathrm{mL}^{-1}$, Table 1 ). The $I C_{50}$ value determined for SDS was $34.30 \pm 2.18 \mu \mathrm{g}_{\mathrm{SDS}} \cdot \mathrm{mL}^{-1}$, which was 3.3-fold lower than the $I C_{50}$ values found for nanoemulsions and multilayer nanoemulsions $\left(112.48 \pm 2.81 \mu \mathrm{g}_{\mathrm{SDS}} \cdot \mathrm{mL}^{-1}\right.$ and $112.81 \pm 7.89 \mu \mathrm{g}_{\mathrm{SDS}} \cdot \mathrm{mL}^{-1}$, respectively, Table 1). These results suggest that the decrease in the cell viability is caused by the presence of the SDS in the nanoemulsions and multilayer nanoemulsions. In fact, SDS is not recognized by EFSA for use in food products (EFSA, 2010), although the FDA approves the use of SDS as surfactant for fruit juice drinks under 25 ppm (CFR, 2014a, 2014b).

Despite of the cytotoxicity of both nanosystems, this work suggests that the use of droplets in the nano-scale by itself did not potentiate the cytotoxic effect of SDS; on the contrary, both nanosystems reduced the cytotoxicity of SDS by 3.3-fold, as can be seen in Table 1. Therefore, in the size ranges studied, cytotoxicity did not seem to be related to size alone, but rather by the presence of SDS (i.e. effect of chemical nature rather than physical size).

\section{Conclusions}

The purpose of this study was to investigate the effect of nanosystems' interfacial composition on their stability during in vitro digestion, on lipids digestibility, curcumin bioaccessibility and antioxidant activity, using a dynamic GI system. In addition, nanosystems' cytotoxicity has been evaluated.

Higher curcumin bioaccessibility was obtained with nanoemulsions, while multilayer nanoemulsions were effective in controlling lipid digestibility, significantly delaying the lipid digestion rate and decreasing the extent of lipid digestion and absorption. Results also suggest that the addition of polyelectrolyte layers was efficient in protecting curcumin from changes in the GI tract, better preserving their antioxidant capacity during digestion. Cytotoxicity assays revealed that the use of nanosystems per se did not influence the cytotoxicity; on the contrary, nanosystems containing SDS were 3.3-fold less toxic than SDS itself.

This study suggests that the developed nanosystems can be used as platforms for the design of functional foods with different functionalities such as increased curcumin bioavailability (i.e. nanoemulsions) or regulation of satiety and reduction of food products caloric intake (i.e. multilayer nanoemulsions). Further studies are needed to evaluate their performance once incorporated in food matrices followed by digestion/ absorption simulation. Moreover, in vivo studies are needed to determine their functionality under more realistic GI conditions.

\section{Conflict of interest}

The authors declared that there is no conflict of interest.

\section{Acknowledgements}

The authors Hélder D. Silva, Ana C. Pinheiro and Miguel A. Cerqueira (SFRH/BD/81288/2011, SFRH/BPD/101181/2014 and SFRH/BPD/72753/2010, respectively) are the recipients of a fellowship from the Fundação para a Ciência e Tecnologia (FCT, Portugal). This work was supported by Portuguese Foundation for Science and Technology (FCT) under the scope of the Project PTDC/AGR-TEC/ $5215 / 2014$, of the strategic funding of UID/BIO/04469/2013 Unit and COMPETE 2020 (POCI-01-0145-FEDER-006684), BioTecNorte operation (NORTE-01-0145-FEDER-000004) funded by the European Regional Development Fund under the scope of Norte2020 - Programa Operacional Regional do Norte, PEst-OE/EQB/LA0004/2011 and iNOVA4Health - UID/Multi/04462/2013, a program financially supported by FCT/Ministério da Educação e Ciência, through national funds and co-funded by FEDER under the PT2020 Partnership Agreement. The authors also acknowledge the European Commission: BIOCAPS (316265, FP7/REGPOT-2012-2013.1). This work was also supported by the "CARINA" project for the safeness, sustainability and competitiveness of agro-food productions of Campania Region. The support of EU Cost Action FA1001 is gratefully acknowledged. The authors also acknowledge Stepan (The Netherlands) for providing the Neobee 1053 oil, and Rui Fernandes from IBMC, University of Porto for assistance in taking the TEM pictures.

\section{References}

Acevedo-Fani, A., Silva, H. D., Soliva-Fortuny, R., Martín-Belloso, O., \& Vicente, A. A. (2017). Formation, stability and antioxidant activity of food-grade multilayer emulsions containing resveratrol. Food Hydrocolloids, 71, 207-215. https://doi.org/10. 1016/j.foodhyd.2017.05.007.

Acevedo-Fani, A., Soliva-Fortuny, R., \& Martín-Belloso, O. (2017). Nanostructured emulsions and nanolaminates for delivery of active ingredients: Improving food safety and functionality. Trends in Food Science \& Technology, 60, 12-22. https://doi. org/10.1016/j.tifs.2016.10.027.

Ahmed, K., Li, Y., McClements, D. J., \& Xiao, H. (2012). Nanoemulsion- and emulsionbased delivery systems for curcumin: Encapsulation and release properties. Food Chemistry, 132(2), 799-807. https://doi.org/10.1016/j.foodchem.2011.11.039.

Burke, S. E., \& Barrett, C. J. (2003b). pH-responsive properties of multilayered poly(1lysine)/hyaluronic acid surfaces. Biomacromolecules, 4(6), 1773-1783. https://doi. org/10.1021/bm034184w.

Burke, S. E., \& Barrett, C. J. (2003a). Acid-base equilibria of weak polyelectrolytes in multilayer thin films. Langmuir, 19(8), 3297-3303. https://doi.org/10.1021/ la026500i.

Cerqueira, M. A., Bourbon, A. I., Pinheiro, A. C., Silva, H. D., Quintas, M. A. C., \& Antonio, A. V. (2013). Edible nano-laminate coatings for food applications. Ecosustainable polymer nanomaterials for food packaging (pp. 221-252). CRC Press.

Cerqueira, M., Pinheiro, A., Silva, H., Ramos, P., Azevedo, M., Flores-López, M., ... Vicente, A. (2014). Design of bio-nanosystems for oral delivery of functional compounds. Food Engineering Reviews, 6(1-2), 1-19. https://doi.org/10.1007/s12393013-9074-3.

CFR (2014a). Code of federal regulations title 21 - Food and drugs $§ 172.822$ sodium lauryl sulfate.

CFR (2014b). Code of federal regulations title 21 - Indirect food additives: Adjuvants, production aids and sanitizers $\S$ Sec. 178.1010 sanitizing solutions.

EFSA (2010). Call for scientific data on food additives permitted in the EU and belonging to the functional classes of emulsifiers, stabilisers and gelling agents. Retrieved 17/ 03/2015, from < http://www.efsa.europa.eu/en/dataclosed/call/ans091123. pdf $>$. 
Guttoff, M., Saberi, A. H., \& McClements, D. J. (2015). Formation of vitamin D nanoemulsion-based delivery systems by spontaneous emulsification: Factors affecting particle size and stability. Food Chemistry, 171, 117-122. https://doi.org/10.1016/j. foodchem.2014.08.087.

Harnsilawat, T., Pongsawatmanit, R., \& McClements, D. J. (2006). Characterization of $\beta$ lactoglobulin-sodium alginate interactions in aqueous solutions: A calorimetry, light scattering, electrophoretic mobility and solubility study. Food Hydrocolloids, 20(5), 577-585. https://doi.org/10.1016/j.foodhyd.2005.05.005.

Hu, M., Li, Y., Decker, E. A., \& McClements, D. J. (2010). Role of calcium and calciumbinding agents on the lipase digestibility of emulsified lipids using an in vitro digestion model. Food Hydrocolloids, 24(8), 719-725. https://doi.org/10.1016/j. foodhyd.2010.03.010.

Hur, S. J., Decker, E. A., \& McClements, D. J. (2009). Influence of initial emulsifier type on microstructural changes occurring in emulsified lipids during in vitro digestion. Food Chemistry, 114(1), 253-262. https://doi.org/10.1016/j.foodchem.2008.09.069.

Jelezova, I., Drakalska, E., Momekova, D., Shalimova, N., Momekov, G., Konstantinov, S., ... Pispas, S. (2015). Curcumin loaded pH-sensitive hybrid lipid/block copolymer nanosized drug delivery systems. European Journal of Pharmaceutical Sciences, 78, 67-78. https://doi.org/10.1016/j.ejps.2015.07.005.

Klinkesorn, U., \& Julian McClements, D. (2010). Impact of lipase, bile salts, and polysaccharides on properties and digestibility of tuna oil multilayer emulsions stabilized by lecithin-chitosan. Food Biophysics, 5(2), 73-81. https://doi.org/10.1007/s11483010-9147-2.

Klinkesorn, U., \& McClements, D. J. (2009). Influence of chitosan on stability and lipase digestibility of lecithin-stabilized tuna oil-in-water emulsions. Food Chemistry, 114(4), 1308-1315. https://doi.org/10.1016/j.foodchem.2008.11.012.

Li, Y., Hu, M., Du, Y., Xiao, H., \& McClements, D. J. (2011). Control of lipase digestibility of emulsified lipids by encapsulation within calcium alginate beads. Food Hydrocolloids, 25(1), 122-130. https://doi.org/10.1016/j.foodhyd.2010.06.003.

Li, Y., Hu, M., Xiao, H., Du, Y., Decker, E. A., \& McClements, D. J. (2010). Controlling the functional performance of emulsion-based delivery systems using multi-component biopolymer coatings. European Journal of Pharmaceutics and Biopharmaceutics, 76(1), 38-47. https://doi.org/10.1016/j.ejpb.2010.05.004.

Liu, F., Ma, C., Zhang, R., Gao, Y., \& Julian McClements, D. (2017). Controlling the potential gastrointestinal fate of $\beta$-carotene emulsions using interfacial engineering: Impact of coating lipid droplets with polyphenol-protein-carbohydrate conjugate. Food Chemistry, 221, 395-403. https://doi.org/10.1016/j.foodchem.2016.10.057.

Maljaars, J., Peters, H. P. F., Haddeman, E., \& Masclee, A. (2009). M2078 Distribution of Small Intestinal Fat Delivery Influences Satiety and Food Intake. Gastroenterology, 136(5), A-480. https://doi.org/10.1016/S0016-5085(09)62212-5.

Malvern, I. (2011). Dynamic light scattering common terms defined.

Mayer, S., Weiss, J., \& McClements, D. J. (2013). Behavior of vitamin E acetate delivery systems under simulated gastrointestinal conditions: Lipid digestion and bioaccessibility of low-energy nanoemulsions. Journal of Colloid and Interface Science, 404, 215-222. https://doi.org/10.1016/j.jcis.2013.04.048.

McClements, D. J. (2010). Design of nano-laminated coatings to control bioavailability of lipophilic food components. Journal of Food Science, 75(1), R30-R42.

McClements, D. J. (2015). Enhancing nutraceutical bioavailability through food matrix design. Current Opinion in Food Science, 4, 1-6. https://doi.org/10.1016/j.cofs.2014. 12.008.

McClements, D. J., \& Li, Y. (2010). Structured emulsion-based delivery systems: Controlling the digestion and release of lipophilic food components. Advances in Colloid and Interface Science, 159(2), 213-228. https://doi.org/10.1016/j.cis.2010. 06.010.

McClements, D. J., \& Xiao, H. (2012). Potential biological fate of ingested nanoemulsions: Influence of particle characteristics. Food \& Function, 3(3), 202-220. https://doi.org/ 10.1039/c1fo10193e.

Minekus, M., Jelier, M., Xiao, J.-Z., Kondo, S., Iwatsuki, K., Kokubo, S., ... Havenaar, R. (2005). Effect of partially hydrolyzed guar gum (PHGG) on the bioaccessibility of fat and cholesterol. Bioscience, Biotechnology, and Biochemistry, 69(5), 932-938. https:// doi.org/10.1271/bbb.69.932.

Mu, H., \& Høy, C.-E. (2004). The digestion of dietary triacylglycerols. Progress in Lipid Research, 43(2), 105-133. https://doi.org/10.1016/S0163-7827(03)00050-X.

Ozturk, B., Argin, S., Ozilgen, M., \& McClements, D. J. (2014). Formation and stabilization of nanoemulsion-based vitamin E delivery systems using natural surfactants: Quillaja saponin and lecithin. Journal of Food Engineering, 142, 57-63. https://doi. org/10.1016/j.jfoodeng.2014.06.015.

Pinheiro, A. C., Bourbon, A. I., Cerqueira, M. A., Maricato, É., Nunes, C., Coimbra, M. A., \& Vicente, A. A. (2015). Chitosan/fucoidan multilayer nanocapsules as a vehicle for controlled release of bioactive compounds. Carbohydrate Polymers, 115, 1-9. https:// doi.org/10.1016/j.carbpol.2014.07.016.

Pinheiro, A. C., Coimbra, M. A., \& Vicente, A. A. (2016). In vitro behaviour of curcumin nanoemulsions stabilized by biopolymer emulsifiers - Effect of interfacial composition. Food Hydrocolloids, 52, 460-467. https://doi.org/10.1016/j.foodhyd.2015.07. 025 .

Pinsirodom, P., \& Parkin, K. L. (2005). Lipase assays. In R. E. Wrolstad (Ed.). Handbook of food analytical chemistry (pp. 371-383). Hoboken, NJ: Wiley.
Porter, C. J. H., Trevaskis, N. L., \& Charman, W. N. (2007). Lipids and lipid-based formulations: Optimizing the oral delivery of lipophilic drugs. Nature Reviews Drug Discovery, 6(3), 231-248 [10.1038/nrd2197].

Rao, J., \& McClements, D. J. (2013). Optimization of lipid nanoparticle formation for beverage applications: Influence of oil type, cosolvents, and cosurfactants on nanoemulsion properties. Journal of Food Engineering, 118(2), 198-204. https://doi.org/ 10.1016/j.jfoodeng.2013.04.010.

Reis, P., Raab, T., Chuat, J., Leser, M., Miller, R., Watzke, H., \& Holmberg, K. (2008). Influence of surfactants on lipase fat digestion in a model gastro-intestinal system. Food Biophysics, 3(4), 370-381. https://doi.org/10.1007/s11483-008-9091-6.

Rufino, M. D. S. M., Alves, R. E., Brito, E. S. D., Morais, S. M. D., Sampaio, C. D. G., PérezJiménez, J., \& Saura-Calixto, F. D. (2007). Metodologia científica: Determinação da atividade antioxidante total em frutas pela captura do radical livre DPPH. Retrieved 22/08/2015, 2015, from < http://www.infoteca.cnptia.embrapa.br/handle/doc/ $426953>$

Salvia-Trujillo, L., Qian, C., Martín-Belloso, O., \& McClements, D. J. (2013). Influence of particle size on lipid digestion and $\beta$-carotene bioaccessibility in emulsions and nanoemulsions. Food Chemistry, 141(2), 1472-1480. https://doi.org/10.1016/j. foodchem.2013.03.050.

Salvia-Trujillo, L., Sun, Q., Um, B. H., Park, Y., \& McClements, D. J. (2015). In vitro and in vivo study of fucoxanthin bioavailability from nanoemulsion-based delivery systems: Impact of lipid carrier type. Journal of Functional Foods, 17, 293-304. https://doi.org/ 10.1016/j.jff.2015.05.035.

Sambuy, Y., De Angelis, I., Ranaldi, G., Scarino, M. L., Stammati, A., \& Zucco, F. (2005). The Caco-2 cell line as a model of the intestinal barrier: Influence of cell and culturerelated factors on Caco-2 cell functional characteristics. Cell Biology and Toxicology, 21(1), 1-26. https://doi.org/10.1007/s10565-005-0085-6.

Silva, H. D., Cerqueira, M. A., Souza, B. W. S., Ribeiro, C., Avides, M. C., Quintas, M. A. C., ... Vicente, A. A. (2011). Nanoemulsions of $\beta$-carotene using a high-energy emulsification-evaporation technique. Journal of Food Engineering, 102(2), 130-135. https:// doi.org/10.1016/j.jfoodeng.2010.08.005.

Silva, H., Cerqueira, M., \& Vicente, A. (2012). Nanoemulsions for food applications: Development and characterization. Food and Bioprocess Technology, 5(3), 854-867. https://doi.org/10.1007/s11947-011-0683-7.

Silva, H. D., Cerqueira, M. A., \& Vicente, A. A. (2015a). Chapter 56 - Nanoemulsion-based systems for food applications. In B. I. Kharisov (Ed.). CRC concise encyclopedia of nanotechnology. USA: CRC Press by Taylor and Francis Group.

Silva, H. D., Cerqueira, M. A., \& Vicente, A. A. (2015b). Influence of surfactant and processing conditions in the stability of oil-in-water nanoemulsions. Journal of Food Engineering, 167(Part B), 89-98. https://doi.org/10.1016/j.jfoodeng.2015.07.037.

Souza, B. W. S., Cerqueira, M. A., Bourbon, A. I., Pinheiro, A. C., Martins, J. T., Teixeira, J. A., ... Vicente, A. A. (2012). Chemical characterization and antioxidant activity of sulfated polysaccharide from the red seaweed Gracilaria birdiae. Food Hydrocolloids, 27(2), 287-292. https://doi.org/10.1016/j.foodhyd.2011.10.005.

Sun, Y., Xia, Z., Zheng, J., Qiu, P., Zhang, L., McClements, D. J., \& Xiao, H. (2015). Nanoemulsion-based delivery systems for nutraceuticals: Influence of carrier oil type on bioavailability of pterostilbene. Journal of Functional Foods, 13, 61-70. https://doi. org/10.1016/j.jff.2014.12.030.

Ting, Y., Jiang, Y., Ho, C.-T., \& Huang, Q. (2014). Common delivery systems for enhancing in vivo bioavailability and biological efficacy of nutraceuticals. Journal of Functional Foods, 7, 112-128. https://doi.org/10.1016/j.jff.2013.12.010.

Tokle, T., Lesmes, U., Decker, E. A., \& McClements, D. J. (2012). Impact of dietary fiber coatings on behavior of protein-stabilized lipid droplets under simulated gastrointestinal conditions. Food \& Function, 3(1), 58-66. https://doi.org/10.1039/ C1FO10129C.

Tokle, T., Lesmes, U., \& McClements, D. J. (2010). Impact of electrostatic deposition of anionic polysaccharides on the stability of oil droplets coated by lactoferrin. Journal of Agricultural and Food Chemistry, 58(17), 9825-9832. https://doi.org/10.1021/ jf101833z.

Troncoso, E., Aguilera, J. M., \& McClements, D. J. (2012). Influence of particle size on the in vitro digestibility of protein-coated lipid nanoparticles. Journal of Colloid and Interface Science, 382(1), 110-116. https://doi.org/10.1016/j.jcis.2012.05.054.

Vachoud, L., Zydowicz, N., \& Domard, A. (2000). Physicochemical behaviour of chitin gels. Carbohydrate Research, 326(4), 295-304. https://doi.org/10.1016/S00086215(00)00038-0.

Zhang, C., Xu, W., Jin, W., Shah, B. R., Li, Y., \& Li, B. (2015). Influence of anionic alginate and cationic chitosan on physicochemical stability and carotenoids bioaccessibility of soy protein isolate-stabilized emulsions. Food Research International, 77, 419-425. https://doi.org/10.1016/j.foodres.2015.09.020.

Zhao, L., Du, J., Duan, Y., Zang, Y. N., Zhang, H., Yang, C., ... Zhai, G. (2012). Curcumin loaded mixed micelles composed of Pluronic P123 and F68: Preparation, optimization and in vitro characterization. Colloids and Surfaces B: Biointerfaces, 97, 101-108. https://doi.org/10.1016/j.colsurfb.2012.04.017.

Zou, L., Zheng, B., Liu, W., Liu, C., Xiao, H., \& McClements, D. J. (2015). Enhancing nutraceutical bioavailability using excipient emulsions: Influence of lipid droplet size on solubility and bioaccessibility of powdered curcumin. Journal of Functional Foods, 15, 72-83. https://doi.org/10.1016/j.jff.2015.02.044. 